\title{
LAS LENGUAS INDÍGENAS EN LA EDUCACIÓN PRIMARIA EN MÉXICO. UNA PROPUESTA EDUCATIVA INTERCULTURAL
}

\section{Indigenous Languages in Primary Education in Mexico. An Intercultural Educational Proposal}

\author{
Jorge Tirzo Gómez*
}

DOI: http://dx.doi.org/10.29043/liminar.v19i2.814

\begin{abstract}
Resumen: Reseña de Sembrando el corazón de nuestra palabra. Las lenguas indígenas como objeto de estudio. Propuesta educativa intercultural para primaria indígena. México, de Graciela Beatriz Quinteros. México: Universidad Autónoma Metropolitana, Unidad Xochimilco, 2019.
\end{abstract}

Abstract: Review of Sembrando el corazón de nuestra palabra. Las lenguas indígenas como objeto de estudio. Propuesta educativa intercultural para primaria indígena. México, de Graciela Beatriz Quinteros. México: Universidad Autónoma Metropolitana, Unidad Xochimilco, 2019.

$\mathrm{E}$ 1 libro Sembrando el corazón de nuestra palabra. Las lenguas indígenas como objeto de estudio. Propuesta educativa intercultural para primaria indígena. México, de Graciela Beatriz Quinteros, es, antes que nada, una propuesta educativa intercultural.

Como toda propuesta educativa, este libro pretende trascender el nivel discursivo e instalarse en el quehacer cotidiano del trabajo docente en las aulas. La obra en su conjunto es la expresión del anhelo colectivo de llevar las reflexiones y los debates característicos de todo proyecto educativo a la concreción de un programa de estudios e incidir en los procesos de enseñanza-aprendizaje de los pueblos indígenas.

El libro contiene las principales ideas en torno a un complejo debate socioeducativo, aquel que se origina en el ámbito de la política educativa nacional en torno a la búsqueda de una mejor educación para los niños indígenas mexicanos, en particular en lo relativo a la enseñanza-aprendizaje de sus lenguas.

\footnotetext{
* Jorge Tirzo Gómez. Doctor en Antropología por la Escuela Nacional de Antropología e Historia (ENAH), México. Titular C en la Universidad Pedagógica Nacional (UPN), Ajusco, México. Temas de especialización: educación intercultural, antropología de la educación, educación
}

En tal sentido, el texto habla del contexto institucional, ideológico, político y disciplinario que implica la construcción de un proyecto educativo, pero esto es solo el inicio, pues una gran parte de la obra contiene los pormenores de una propuesta educativa que va de la teoría lingüística, al ámbito de la pedagogía y, finalmente, el conjunto se expresa en un planteamiento programático-didáctico.

El proceso que se narra dio inicio en el año 2003, con la compleja tarea de elaborar una propuesta educativa para la creación de las nuevas asignaturas en lenguas indígenas. A partir de ese punto, la tarea llevó a la integración de equipos de trabajo conformados por profesores hablantes de las diferentes lenguas que darían inicio a este ejercicio educativo, tarea que también integraría a expertos en educación, pedagogía, lingüística y otras especialidades, que se enfocaron en la elaboración de programas de estudio y materiales educativos. indígena. Correo electrónico: jtirzzo@gmail.com. ORCID: https:/orcid.
org/0000-0002-1380-4046

Recibida: 29 de mayo de 2020

Aprobada: 17 de septiembre de 2020 
La obra de Graciela Quinteros tiene como preocupación central las lenguas maternas indígenas en México; su expresión social, su dosificación programática, sus vínculos culturales, las posibilidades cognoscitivas y los retos educacionales.

Como es lógico pensar, la elaboración de una propuesta educativa de estas dimensiones no es una tarea que pueda construir una sola persona, ni siquiera una sola institución; para lograrlo fue necesario convocar a diversos participantes: a) se invitó a docentes hablantes de sus lenguas y expertos en el campo educativo, y b) participaron instituciones públicas dedicadas a la educación indígena. En cuanto a los primeros, la obra da cuenta de la participación de profesores hablantes de lenguas indígenas, académicos, asesores y especialistas. En relación con las instituciones, participaron la Secretaría de Educación Pública (SEP), la Dirección General de Educación Indígena (DGEI), la Universidad Autónoma de México (UAM), la Universidad Pedagógica Nacional (UPN), la Universidad Nacional Autónoma de México (UNAM), la Universidad Autónoma de Chiapas (UNACH), la Universidad Intercultural de Chiapas (UNICH), la Universidad Veracruzana Intercultural (UVI), la Escuela Nacional de Antropología e Historia (ENAH) y un cuantioso número de escuelas primarias indígenas.

En este libro, la contribución de Graciela Quinteros consiste en dar cuenta de todo el proceso, en sistematizar las acciones y darles un orden que permita a los lectores un acercamiento secuencial y sistemático. Sin embargo, el desarrollo de la construcción de la propuesta, con sus debates, acuerdos y desacuerdos, es propiedad de un colectivo heterogéneo de profesionistas que se expresa en cada una de las páginas. Como las lenguas - las culturas y las prácticas sociales del lenguaje-, la propuesta educativa intercultural que está contenida en la obra no es propiedad individual. Su relevancia estriba en representar el trabajo colectivo, y contiene amplios saberes y anhelos de los pueblos indígenas.

La obra puede comprenderse en dos partes. La primera, por los elementos que contiene se podría denominar "la política educativa y el contexto institucional", mientras la segunda es la parte a la que se le dedican mayor número de páginas, pues propiamente contiene "la propuesta educativa intercultural".

En cuanto a la primera parte, el inicio del proceso que se narra en el libro está marcado por la puesta en práctica de la Reforma Educativa, que por aquellos años promovió el Estado mexicano para tratar de afrontar las problemáticas de la educación indígena, razón por la cual el contexto institucional de estas tareas está expresado por la Secretaría de Educación Pública (SEP), y en particular por la Dirección General de Educación Indígena (DGEI).

Dado ese contexto, el libro narra las situaciones a las que se enfrentó un amplio grupo de profesionales al que le fue encargada esta tarea educativa. De los retos, logros y dificultades que había que encarar, los que la misma autora denomina "decisiones difíciles".

Un relato de estas características necesariamente refiere a funcionarios, especialistas, procesos académicos y productos preliminares, de tal suerte que en las páginas del libro podemos encontrar personajes fundamentales en todo ese proceso: funcionarios y maestros directamente vinculados con la DGEI, especialistas de universidades y profesores hablantes de diferentes lenguas indígenas que se integraron a las Comisiones Estatales e Interestatales. Todos ellos perseguían la concreción de los programas y de los materiales de apoyo de las asignaturas en lenguas indígenas, objetivo que implicó la elaboración de otros productos parciales, pero igualmente importantes, como los parámetros curriculares, la construcción de una política curricular, la definición de las prácticas sociales del lenguaje, la redacción de los libros cartoneros, y el diseño de un Diplomado de Diseño Curricular y de un Taller de Normalización de la Escritura.

Esta primera parte puede ubicarse en la presentación e introducción del libro, secciones que dan cuenta del contexto institucional, organizacional y de toma de decisiones que una propuesta de tal naturaleza implica.

La introducción del libro permite visualizar cuatro grandes momentos que involucran el trabajo de las comisiones, los productos de trabajo y una periodicidad temporal. Estos cuatro momentos son los siguientes: 
1. De 2003 a 2006. Primer momento, caracterizado por la conceptualización y el desarrollo de los denominados "parámetros curriculares", en los cuales se sitúa como eje fundamental el lenguaje como objeto de estudio.

2. 2008. Segundo momento. Publicación por parte de la SEP-DGEI de los parámetros curriculares. En este periodo dan inicio los trabajos de la primera generación de las comisiones de las lenguas maya, hñahñú, tutunakú y náhuatl.

3. 2014. Tercer momento. Integración de nuevas comisiones que dieron origen a las generaciones segunda y tercera. La segunda generación trabajó las asignaturas de las lenguas tsotsil, tseltal, tojolab’al y ch'ol y, la tercera generación, las lenguas náayeri y tepehua.

4. 2016 y 2017. Cuarto momento, caracterizado por la adecuación de los programas de estudio, periodo que coincide con los tiempos y objetivos de la Reforma Educativa de 2017-2018 planteada por la SEP.

La segunda parte, "La propuesta educativa intercultural", contiene los elementos que integran propiamente el planteamiento educativo. En esta parte se expresan las ideas y acuerdos de las múltiples sesiones de esos años de trabajo. El producto final es una propuesta educativa que ubica como eje de la reflexión el trabajo y las acciones educativas en cuanto a las lenguas indígenas como objeto de estudio.

La Propuesta Educativa Intercultural para Primaria Indígena se encuentra organizada en los siguientes apartados: "Propósitos", "Enfoque educativo", "Enfoque del lenguaje: la noción de prácticas sociales del lenguaje", "Las prácticas de la tradición oral como objetos de conocimiento", "Organización curricular", "Mapas curriculares y cuadros de contenidos mínimos", "Enfoque didáctico: proyectos didácticos y actividades recurrentes", "Dosificación de los aprendizajes esperados" y "Propuesta de evaluación y perfil docente".

Cada apartado explicita con claridad y precisión las ideas que estructuran la propuesta educativa. Cabe señalar que existe una congruencia entre cada uno de los aspectos y el producto final, lo que permite observar un trabajo arduo y cuidadoso del todo y sus componentes. Con esto se entiende que existe una estructura pertinente que expresa un manejo correcto de los aspectos teóricos de la lengua y los procesos de aprendizaje infantiles, y los correlaciona con una estructuración curricular acertada que plantea perspectivas institucionales en torno a los conocimientos, a la vez que define un planteamiento didáctico que abre la posibilidad creativa de la actividad docente.

En esta perspectiva, en el libro se definen procesos y secuencias de enseñanza-aprendizaje que permiten observar los propósitos educativos en torno a las lenguas indígenas concebidas como objetos de estudio.

Además de esos elementos estructurantes, el carácter de propuesta educativa intercultural se aprecia con toda claridad a través de una serie de conceptos centrales que sirven de referentes para la comprensión de las intenciones educativas que la obra postula.

Esos conceptos centrales son: "Enseñanza situada", "El buen vivir", "Educación intercultural bilingüe y bi-alfabetización", "Prácticas sociales del lenguaje", "Prácticas de la tradición oral", "Trabajo por proyectos", "Actividades recurrentes", "Talleres" y los "Libros cartoneros". Cada concepto es cuidadosamente abordado, desarrollado, ejemplificado e inserto en una lógica curricular que permite visualizar con claridad sus posibilidades de trabajo en el aula, sin dejar de referir a la dimensión social, que es la que le da sentido y trascendencia.

Sin duda la obra nos abre un panorama de trabajo con ideas sólidas y bien estructuradas, pero no es más que el inicio, porque un planteamiento importante contenido en esta propuesta es que, para que todo eso se haga posible, el trabajo fundamental le corresponde a los docentes de educación indígena. Por su parte, la educación indígena requiere urgentemente un giro epistemológico y metodológico que brinde a los niños indígenas la posibilidad de usar su lengua, aprender otra, recuperar su cultura y tradiciones y darle usos sociales, tanto de manera oral como escrita.

En esta obra, Graciela Quinteros comprende esa tarea y pretende contribuir a proponer una mejor edu- 
cación para las niñas y los niños indígenas que la que hasta ahora se les ha ofrecido. En sus propias palabras podemos encontrar ese compromiso: "El propósito central de este esfuerzo colectivo es abatir la castellanización en el contexto escolar, por ser un instrumento de una política asimilacionista que genera un bilingüismo sustractivo, propio del horizonte colonial aún vigente".

En este sentido, el libro Sembrando el corazón de nuestra palabra. Las lenguas indígenas como objeto de estudio. Propuesta educativa intercultural para primaria indígena.
México, es una alternativa educativa para ser puesta en práctica por docentes, escuelas, instituciones educativas y comunidades indígenas.

Como la misma autora lo señala, este relato es "una versión entre tantas posibles", pues cada persona que participó tendrá su propio punto de vista. Sin embargo, la perspectiva que nos ofrece Graciela Quinteros está cargada de una serie de vivencias íntimamente ligadas al trabajo docente, el valor de las lenguas y la esperanza de un mejor futuro para los niños indígenas. 